\title{
Histopathological evaluation of endometrium in Postmenopausal bleeding
}

\author{
Chiragkumar B Menapara ${ }^{1, *}$, Killol N Desai ${ }^{2}$ \\ ${ }^{1,2}$ Assistant Professor, ${ }^{1,2}$ Dept. of Pathology, ${ }^{1,2}$ GMERS Medical College and Hospital, Junagadh, Gujarat, India
}

*Corresponding Author:

Email: chirmen123@gmail.com

\begin{abstract}
Aims \& Objectives: 1. To evaluate various causes of postmenopausal bleeding in terms of functional and organic endometrial lesions on histopathological basis, 2. To confirm or to rule out the diagnosis of atypical or malignant endometrial lesions. 3 . To help the gynecologists in diagnosis of endometrial cancer as early as possible.

Materials and Methods: The study was carried out in the Department of Pathology, GMERS Medical College-Junagadh from January 2015 to September 2018 and includes 200 cases of postmenopausal women who presented with bleeding problems at our institute. Histopathological evaluation of endometrium was done in all these cases after clinical evaluation and final diagnosis was given in terms of organic or functional lesions.

Results: Out of 200 cases, 36 cases (18\%) showed organic lesions \& 164 cases (82\%) showed functional lesions. Among organic lesions, Simple \& Typical Hyperplasia was the commonest one (12 cases), while among functional lesions, Atrophic Endometrium was the commonest one (88 cases). Atypical and Malignant lesions were commonly seen after 60 years of age.

Conclusion: The role of histopathology remains always important in the evaluation of postmenopausal bleeding. Careful histopathological evaluation of endometrium is always necessary in order to confirm or to rule out premalignant or malignant lesions in order to save the patient's life.
\end{abstract}

Keywords: Postmenopausal Bleeding, Organic Lesions, Functional Lesions.

\section{Introduction}

Menopause is defined as the time of cessation of ovarian function resulting in permanent amenorrhoea. It takes 12 months of amenorrhoea to confirm that menopause has set in, and therefore it is a retrospective diagnosis. ${ }^{1}$ The word menopause itself is derived from two Greek words namely Meno (month) and Pause (to stop). ${ }^{2}$ It is a physiological event that indicates the end of reproductive life of a woman and is associated with signs and symptoms of Hormone (Estrogen) deficiency. It also has a considerable impact on overall health and on quality of life of a woman.

Average age of menopause of an Indian woman is 46.2 years much less than their Western counter parts (51 years). ${ }^{3}$ Gynecological problems associated with menopause include postmenopausal bleeding, genital prolapse, pelvic inflammation, etc. Vaginal bleeding occurring any time after 6 months of amenorrhoea in menopausal age should be considered as postmenopausal bleeding and investigated. ${ }^{1}$ Postmenopausal bleeding clinically represents as heavy bleeding, just spotting or just like normal menstruation. ${ }^{4}$

Even without amenorrhoea or irregular bleeding, if a woman over the age of 52 years continues to menstruate, she needs investigations to rule out endometrial hyperplasia and malignancy of the genital tract. ${ }^{1}$ The dictum is "postmenopausal bleeding indicates malignancy until proved otherwise".

Therefore, aims and objectives of this present study are 1) to evaluate and study various causes of postmenopausal bleeding in terms of functional and organic endometrial lesions on histopathological basis,
2) to confirm or to rule out the diagnosis of atypical or malignant endometrial lesion in order to make a firm decision about patient's management and to avoid unnecessary radical surgery and 3) to help the gynecologists in diagnosis of endometrial cancer as early as possible in order to improve chances of cure and to save the patient's life.

\section{Materials and Methods}

The present study was carried out in the Department of Pathology, GMERS Medical CollegeJunagadh from January 2015 to September 2018 for a period of 3 years and 9 months. It includes a total number of 200 cases of postmenopausal women who presented with bleeding problems at the Department of Gynecology of our institute.

Women with age of 50 years or above having a definite history of natural menopause or complete cessation of menstrual cycles for more than 12 months were included in this study while those with age of less than 50 years, having history of premature menopause (before 40 years) either natural or surgical, having history of hormone replacement therapy (HRT) for last 6 months or having history and other findings suggestive of cervical or adnexal lesions including cervical cancer were not included. Nature of specimens includes endometrial biopsies by dilatation \& curettage (D \& C), hysterectomies, hysterectomies with unilateral salpingoophorectomy and hysterectomies with bilateral salpingoophorectomy.

These specimens were directly sent from Gynecology Department with relevant clinical details in a specific performa. Gross examination of specimens 
and microscopic examination of their formalin fixed, paraffin embedded and $\mathrm{H} \& \mathrm{E}$ stained tissue sections were performed at the histopathology laboratory and findings were noted. On the basis of both gross and microscopic findings, final diagnosis was given in the form of histopathology report.

For this present study, relevant and sufficient data was collected from both previous and present (current) histopathology laboratory registers and analysis was performed. Comparative evaluation of this present study was done with other similar studies and final conclusion was given.

\section{Results}

Total 200 cases were enrolled in this present study. Endometrial lesions leading to postmenopausal bleeding were broadly categorized into two main groups: 1) Functional \& 2) Organic. Details are mentioned below in Table 1.

Table 1: Categorization of various endometrial lesions in PMB

\begin{tabular}{|l|l|}
\hline Functional Lesions or Causes & Proliferative Endometrium \\
\cline { 2 - 2 } & Disordered Proliferative Endometrium \\
\cline { 2 - 2 } & Secretory Endometrium \\
\cline { 2 - 2 } Organic Lesions or Causes & Atrophic Endometrium \\
\cline { 2 - 2 } & Endometritis \\
\cline { 2 - 2 } & Endometrial Polyp \\
\cline { 2 - 2 } & Simple Endometrial Hyperplasia \\
\cline { 2 - 2 } & Complex Endometrial Hyperplasia \\
\cline { 2 - 2 } & Endometrial Hyperplasia with Atypia \\
\cline { 2 - 2 } & Endometrial Carcinoma \\
\hline
\end{tabular}

Out of 200 cases, only $36(18 \%)$ were found to have organic lesions while $164(82 \%)$ were found to have functional lesions. Distribution of these cases is mentioned below in Table 2

Table 2: Distribution of cases on the basis of histopathological diagnosis in PMB

\begin{tabular}{|l|c|c|}
\hline Diagnosis on the basis of HPE & No. of Cases & Percentage \% \\
\hline Atrophic Endometrium & 88 & 44 \\
\hline Proliferative Endometrium & 42 & 21 \\
\hline Secretory Endometrium & 18 & 09 \\
\hline Disordered Proliferative Endometrium & 16 & 08 \\
\hline Total (Functional) & $\mathbf{1 6 4}$ & $\mathbf{8 2}$ \\
\hline Endometritis & 06 & 03 \\
\hline Endometrial Polyp & 04 & 02 \\
\hline Simple Endometrial Hyperplasia & 12 & 06 \\
\hline Complex Endometrial Hyperplasia & 06 & 03 \\
\hline Endometrial Hyperplasia with Atypia & 03 & 1.5 \\
\hline Endometrial Carcinoma & 05 & 2.5 \\
\hline Total (Organic) & $\mathbf{3 6}$ & $\mathbf{1 8}$ \\
\hline
\end{tabular}

From all details mentioned above in Table 2, it is obvious that functional lesions are more common than organic lesions. Among functional lesions, Atrophic endometrium is the commonest one followed by Proliferative endometrium. Among organic lesions,
Simple endometrial hyperplasia without Atypia is the commonest one.

In this study, minimum age of patient was 50 years while maximum age was 74 years. Distribution of study subjects or cases according to their age group is mentioned below in Table 3

Table 3: Distribution of study subjects or cases according to their age group $(\mathbf{n}=\mathbf{2 0 0})$

\begin{tabular}{|l|c|c|c|c|c|}
\hline \multirow{2}{*}{ Histopathological Diagnosis } & \multicolumn{6}{|c|}{ Age Groups } \\
\cline { 2 - 7 } & $\mathbf{5 0 - 5 4}$ & $\mathbf{5 5 - 5 9}$ & $\mathbf{6 0 - 6 4}$ & $\mathbf{6 5 - 6 9}$ & $\mathbf{7 0 - 7 4}$ \\
\hline Atrophic Endometrium & 24 & 14 & 27 & 13 & 10 \\
\hline Proliferative Endometrium & 22 & 10 & 6 & 4 & --- \\
\hline Secretory Endometrium & 13 & 3 & 1 & 1 & --- \\
\hline $\begin{array}{l}\text { Disordered Proliferative } \\
\text { Endometrium }\end{array}$ & 10 & 4 & 1 & 1 & --- \\
\hline
\end{tabular}




\begin{tabular}{|l|c|c|c|c|c|}
\hline Endometritis & 4 & 1 & 1 & --- & --- \\
\hline Endometrial Polyp & 3 & 1 & --- & --- & --- \\
\hline Simple Endometrial Hyperplasia & 1 & 6 & 5 & --- & --- \\
\hline Complex Endometrial Hyperplasia & 1 & 1 & 3 & 1 & --- \\
\hline Endometrial Hyperplasia with Atypia & --- & 1 & 2 & --- & --- \\
\hline Endometrial Carcinoma & 1 & --- & 2 & 2 & --- \\
\hline Total & 79 & 41 & 48 & 22 & 10 \\
\hline
\end{tabular}

From details mentioned above in Table 3 , it is obvious that functional lesions like normal proliferation, disordered proliferation, secretory changes, etc and organic lesions like polyp, inflammation, simple \& typical hyperplasia, etc are commonly seen before 60 years of age while complex hyperplasia, atypical hyperplasia \& carcinoma are commonly seen in women having age of 60 years or above. Atrophy of endometrium can be seen in all age groups of menopausal age. In this present study, total 5 cases of endometrial adenocarcinomas are included and 4 out of them are elderly women with age of 60 years or above. Mean age of diagnosis of Malignancy is 62 years in this present study.

Therefore, it is necessary and advisable to examine endometrial tissue under microscope in each and every case of postmenopausal bleeding particularly those who are beyond 60 years of age in order to confirm or rule out the diagnosis of atypical or malignant lesions.

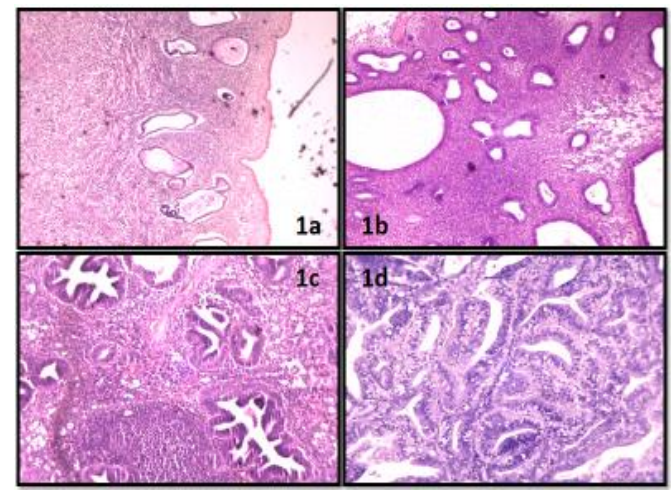

Fig. 1: shows diagrams or microscopic images of various endometrial lesions

Fig. 1 shows diagrams or microscopic images of various endometrial lesions. 1a shows Atrophic changes of endometrium with cystic dilatation of glands and thinning of stroma. 1b shows Simple Endometrial Hyperplasia with characteristic Swiss cheese pattern. 1c shows Complex Endometrial Hyperplasia with back to back arrangement of glands and Branching pattern. 1d shows Endometrial Adenocarcinoma with true papillae formation having fibro-vascular core. All these diagrams are direct microscopic photographs of $\mathrm{H} \& \mathrm{E}$ stained sections of endometrial tissue under low power magnification (100x).

\section{Discussion}

Bleeding per vaginum after end of reproductive life of a woman indicates some underlying pathology of either uterine corpus or uterine cervix and one should check for premalignant or malignant conditions leading to this problem in order to save patient's life. Our present study includes 200 cases of women with confirmed clinical diagnosis of postmenopausal bleeding and further histopathological evaluation of endometrium for the same problem. Out of them, $82 \%$ cases show functional or non-organic changes of endometrium and $18 \%$ cases shows organic lesions. In other similar study like that done by Sonia Gon et al, ${ }^{5}$ out of 151 cases, 121 cases $(80.1 \%)$ show non-organic lesions while 30 cases (19.9\%) show definite organic endometrial pathology. In another similar study done by Vaidya $\mathrm{S}$ et $\mathrm{al}^{6}$ there are $81 \%$ functional endometrial lesions and $19 \%$ organic endometrial lesions. So it is now obvious that organic causes are not commonly seen as compared to functional ones but one should check for them before giving any particular treatment.

Atrophy of endometrium is the commonest functional cause for postmenopausal bleeding followed by normal proliferative endometrium. In our present study, $44 \%$ cases show atrophy of endometrium. In a study done by Karmarkar P et $\mathrm{al}^{7} 32 \%$ cases show atrophy of endometrium. The incidence of atrophy is found to be $49.9 \%$ by Gredmark T et al, ${ }^{8} 52.1 \%$ by Lee WH et al, ${ }^{9} 64.4 \%$ by Dangal $\mathrm{G}$ et $\mathrm{al}^{10}$ and $53 \%$ by Kaur $\mathrm{M}$ et al. ${ }^{11}$ They all reported endometrial atrophy as the commonest finding in patients with postmenopausal bleeding which is consistent with the present study. Cystic changes of endometrial glands, thinning of stroma and sclerotic changes of blood vessels may be the underlying reasons for bleeding in atrophic endometrium.

Simple endometrial hyperplasia without atypia constitutes the commonest organic cause for postmenopausal bleeding. Our present study shows 12 such cases $(6 \%)$. In a study done by Mallick $\mathrm{A}$ et $\mathrm{al}^{12}$ simple hyperplasia without atypia is found in $8.34 \%$ cases. In other studies like those done by Karmarkar P et $\mathrm{al}^{7}$ and Ahmed JA, ${ }^{13}$ results are $21.2 \%$ and $26.6 \%$ respectively that are somewhat higher as compared to our present study. Endometrial hyperplasia itself is a clinically and pathologically significant condition. It is one of the predisposing factors that lead to development of endometrial carcinoma. The risk is particularly higher in case of hyperplasia with nuclear atypia. Atypical hyperplasia either simple or complex in nature 
can be considered as an immediate precursor of adenocarcinoma and management of the patient is more or less similar in both cases. In our present study, endometrial hyperplasia with atypia is found in 3 cases $(1.5 \%)$ only. In the similar studies done by Karmarkar P et $\mathrm{al}^{7}$ and Mallick A et $\mathrm{al},{ }^{12}$ it is found in $7.2 \%$ cases and $0.93 \%$ cases respectively.

Endometrial carcinoma is the most dangerous organic lesion that leads to postmenopausal bleeding. Our present study shows 5 such cases $(2.5 \%)$. In other studies like those done by Sreelatha $\mathrm{S}$ et al. ${ }^{14}$ Karmarkar $\mathrm{P}$ et al, ${ }^{7}$ Mallick A et al ${ }^{12}$, results are $4.0 \%$, $3.6 \%$ and $9.28 \%$ respectively. Mean or average age of presentation of endometrial carcinoma in this present study is 62 years. According to Key Statistics for Endometrial Cancer - American Cancer Society, Endometrial cancer affects mainly postmenopausal women. The average age of women diagnosed with endometrial cancer is 60 . It is uncommon in women under the age of $45 .{ }^{15}$ So, result of our present study is quite comparable with that of others.

Tubercular Endometritis or Endometrial Tuberculosis is also responsible for certain cases of postmenopausal bleeding. Mallick A et $\mathrm{al}^{12}$ reported $0.93 \%$ of Endometrial Tuberculosis while Karmarkar P et $\mathrm{al}^{7}$ reported $0.40 \%$ of such cases. Sousa $\mathrm{R}$ et al reported endometrial tuberculosis in $1.4 \%$ cases. ${ }^{16}$ In our present study, we have not reported any case of Endometrial Tuberculosis.

In our present study, we have included only endometrial lesions both non-organic and organic leading to postmenopausal bleeding. However, myometrial, cervical and adnexal lesions are also responsible in certain cases. Leiomyoma or Fibroid of uterus is one of the common causes for such problem. Leiomyoma is usually seen during reproductive period of life and gradually reduces in size after menopause due to lack of hormonal stimulation. It usually leads to bleeding problems (AUB) during Pre-menopausal and Peri-menopausal period of life. However, it is also seen in certain cases of postmenopausal bleeding. Karmarkar $\mathrm{P}$ et $\mathrm{al}^{7}$ has reported $4.0 \%$ of such cases.

Carcinoma of Cervix, most commonly of squamous type (SCC) is also responsible for certain cases of postmenopausal bleeding. Although it is a malignancy of relatively younger females who are in their reproductive period or perimenopausal period of life, certain cases are seen in postmenopausal women also. Karmarkar $\mathrm{P}$ et $\mathrm{al}^{7}$ has reported $6.4 \%$ of such cases. Malignant mixed mullerian tumor (MMMT) is also a rare cause of Postmenopausal bleeding. In our present study, we have not reported such rare entity.

\section{Conclusion}

Postmenopausal bleeding is a serious gynecological problem and it is a condition that alarms some underlying pathology. Both functional as well as organic lesions of endometrium lead to this problem. In elderly women particularly above 60 years of age, the risk of premalignant and malignant lesions of endometrium is higher as compared to younger women. Apart from endometrial lesions, myometrial \& cervical lesions also lead to bleeding in certain cases. Therefore, the role of histopathology remains always important in the diagnosis of postmenopausal bleeding. Careful histopathological evaluation of endometrium is always necessary in order to confirm or to rule out premalignant or malignant lesions as it helps the gynecologists to save the patient's life and also avoids unnecessary radical surgeries.

\section{Conflict of Interest: None}

\section{References}

1. Padubidri VG, Daftary SN. Howkins \& Bourne Shaw's Textbook of Gynecology. 16/e. Ch. 5. New Delhi: Reed Elsevier India Private Limited; 2015.

2. Dawood NS, Peter K, Ibrar F, Dawood A. Postmenopausal bleeding: causes and risk of genital tract malignancy. J Ayub Med Coll Abbottabad 2010;22:117-20.

3. Maninder Ahuja. Age of menopause and determinants of menopause age: A PAN India survey by IMS. $J$ Midlife Health 2016;7(3):126-31.

4. Khan RL. Postmenopausal bleeding. In text book of Gynecology, 3rd edition. Medical Publications, Lahore 2000;260-62.

5. Gon S, Kundu T, Mallick D, Ghosh G. A Study on Histopathological Patterns of Endometrium in Different Types of Abnormal Uterine Bleeding Among Peri and Postmenopausal Women. IOSR J Dent Med Sci 2016;15(9):106-11.

6. S Vaidya, M Lakhey, S Amatya Vaidya, PK Sharma, S Hirachand, S Lama and S KC.Histopathological pattern of abnormal uterine bleeding in endometrial biopsies. Nepal Med Coll J 2013;15(1):74-7.

7. Karmarkar P, Wilkinson A, Rathod M. Histopathological Evaluation of Postmenopausal Bleeding. IOSR J Dent Med Sci 2014;13(10):53-7.

8. Gredmark T, Sonja Kvint, Guillaume Havel, Lars Ake Maltsson. Histopathological findings in women with postmenopausal bleeding. Br J Obstet Gynecol 1995;102:133-36.

9. Lee WH, Tan KH, Lee YW. The aetiology of postmenopausal bleeding--a study of 163 consecutive cases in Singapore. Singapore Med J 1995;36(2):16468.

10. Dangal G. A Study of Endometrium of Patients with Abnormal Uterine Bleeding at Chit Wan Valley. Kathmandu Univ Med J 2003;1:110-12.

11. Kaur M, Singh R, Sharma M. Endovaginal Sonographic Evaluation of Postmenopausal Uterine Bleeding. J Clin Diag Res 2010;4:2175-82.

12. Mallick A, Behera R, Subudhi K. Histopathological Study of Endometrium in Postmenopausal Bleeding. $J$ Evol Med Dent Sci 2013;2(46):9010-18.

13. Ahmed JA. Clinico Pathological Evaluation of Postmenopausal Uterine bleeding in Mosul City. Tikrit Med J 2007;13:73-8.

14. Sreelatha S, Jayanthi SP, Shivananjaiah C, Malapure P, HN Nataraj. Postmenopausal bleeding and its evaluation: Prospective study in a tertiary care center. Int J Clin Obstet Gynecol 2017;1(2):48-51. 
15. Key Statistics for Endometrial Cancer [Internet] 2018 [Last Revised on 2018 Jan 4]. Available from: https://www.cancer.org/cancer/endometrialcancer/about/key-statistics.html

16. Sousa R, Silvestre M, Almeida e Sousa L, Falcão F, Dias I, Silva T, De Oliveira C, et al. Transvaginal ultrasonography and hysteroscopy in postmenopausal bleeding: a prospective study. Acta Obstet Gynecol Scand 2001;80:856-62.
How to cite the article: Menapara C.B, Desai K.N. Histopathological evaluation of endometrium in Postmenopausal bleeding. Arch Cytol Histopathol Res 2018;3(4):201-205. 